\title{
Phenomenological-narrative contributions to understand the narrative strategies that shape the autobiographical account throughout different moments of the therapeutic process
}

\author{
Dante Gabriel Duero, ${ }^{1}$ Francisco Javier Osorio Villegas ${ }^{2,3}$ \\ ${ }^{1}$ Department of Psychology, National University of Córdoba, Córdoba, Argentina; ${ }^{2}$ Doctoral Program in Psychology, School of Social \\ Sciences, University of Chile, Santiago, Chile; ${ }^{3}$ Millennium Institute for Depression and Personality Research (MIDAP), Chile
}

\begin{abstract}
Different studies suggest that the strategies and narrative styles that people use to construct their autobiographical accounts have repercussions on their self-organization, as well as on their identity experience and their conception of the world. Empirical evidence supports changes in different aspects related to process, structure, and content in the narrative of clients during the course of the therapeutic process;

Correspondence: Francisco Javier Osorio Villegas, Department of Social Sciences, University of Chile, Avda. Capitán Ignacio Carrera Pinto 1045, Nuñoa, 6850331, Santiago de Chile, Chile. Tel.: +562.29787805 .

E-mail: francosovil@yahoo.es

Citation: Duero, D.G., Osorio Villegas, F.J., Phenomenologicalnarrative contributions to understand the narrative strategies that shape the autobiographical account throughout different moments of the therapeutic process. Research in Psychotherapy: Psychopathology, Process and Outcome, 21(2), 98-115. doi: 10.4081/ripppo.2018.309

Contributions: the authors contributed equally.

Conflict of interest: the authors declare no potential conflict of interest.

Acknowledgments: the authors would like to thank the Millennium Institute for Depression and Personality Research (MIDAP) of Santiago, Chile, for having granted them access to their database these, in turn, seem to condition the course and the results of the process. In this paper we will seek to show, based on a case study and through the application of a method of phenomenological-narrative analysis, what are the predominant narrative strategies that a client uses in order to shape her autobiographical narrative in the initial and final moments of her psychotherapeutic process. Our data suggest that the narrative strategies at the beginning and end of the therapy are qualitatively differentiable. Changes are observed in the plot of the respective accounts, as well as a differentiated mode in the use of narrative functions. More specifically toward the end of psychotherapy, the client makes a deeper characterization of herself and others, based on predicates of a subjectivating, interpretive, and evaluative-reflective kind. She also predominantly uses proconcluding metacomments, which could facilitate the integration of problematic experiences. In summary, our data suggest that after a successful therapeutic process the client uses more complex and integrated narrative strategies for the construction of her autobiographical account.
\end{abstract} for this study.

Funding: this study was supported by the Secretaría de Ciencia y Técnica (SECYT) of the National University of Córdoba (grant No. 30720150100202CB), the Comisión Nacional de Investigación Científica y Tecnológica of Chile (CONICYT) (grant No. 7613/2017) and by the Fund for Innovation and Competitiveness (FIC) of the Chilean Ministry of Economy, Development and Tourism, through the Millennium Science Initiative (grant No. IS130005).

Ethical statement: this research has been carried out from secondary data provided by the MIDAP. The authors have a copy of the loan agreement. Also, the client who participated in the study has signed an informed consent accepting the use of the data for research and dissemination purposes. Finally, all personal data have been modified in order to preserve the participant's identity.

Received for publication: 18 April 2018.

Revision received: 27 July 2018.

Accepted for publication: 31 July 2018.

This work is licensed under a Creative Commons Attribution NonCommercial 4.0 License (CC BY-NC 4.0).

CCopyright D.G. Duero, F.J.O Villegas, 2018

Licensee PAGEPress, Italy

Research in Psychotherapy:

Psychopathology, Process and Outcome 2018; 21:98-115

doi:10.4081/ripppo.2018.309
Key words: Autobiographical narrative construction; Narrative analysis model; Narrative research in psychotherapy; Therapeutic. change; Therapeutic process..

\section{Introduction}

The term narrative has different meanings in social sciences. Narrative can be understood as an object of study and as a discourse and literary genre; as a cognitive way of processing information; and as a research method (Bamberg, 2012).

With regard to narrative as an object of study, attempts have been made to differentiate it from other types of discourse. This has led to the study of narrative productions such as stories. Brockmeier and Harré (1991) state that narrative discourse is identified by its structure: that is, stories have a beginning, a development, and a denouement. Ricoeur $(1978,2004)$ points out that one of the main elements of every narrative is its diachronic nature. A general characteristic of accounts and stories is that they describe a diachrony where different events sepa- 
rated in time are articulated coherently. According to Bruner (2003), a story requires a cast of characters who are free agents with their own expectations. The crux of the story involves an unexpected event or consequence. The action in the story describes the protagonist's attempts to overcome an event that occurs unexpectedly or that constitutes a violation of a community's canons or expectations. The end involves some type of solution to the problem or conflict.

On the other hand, Ricoeur (2004) proposes that narrative is, at the same time, a cognitive way of processing and making sense of the experience; he says that it might be the gravitational nucleus of our cognitive schemata to represent human actions. Ricoeur (1978) believes that the same temporal and narrative form of structure underlies both stories and our understanding of human actions. Within the characteristic schema of narrative discourse, actions and events are interpreted in the light of the story's denouement. Something similar occurs when we think of human actions in terms of intentions and purposes. According to Ricoeur, narrative might represent a form of essential cognitive architecture that is especially necessary to arrange events involving human agents acting on the basis of reasons. Following this line of thought, Bruner (2004) and Polkinghorne (1988) have proposed that narrative might be like a distaff, a matrix thanks to which, at a cognitive level, we configure everyday experience as a framework that develops over time and has meaning and direction. We insert the events in our lives, particularly when they are unexpected, into a plot that makes it possible for us to understand its evolution. In addition, these events are read according to their implication for characters acting on the basis of motives and reasons.

Finally, with regard to narratives as a method and a tool for analysis, at least three ways of approaching their study as an object have been offered by: i) studying the microstructural elements that determine topical cohesiveness (Lavov \& Waletsky, 1967); ii) analyzing macrostructural aspects such as the storyline, the plot, and the different functions performed by the characters in the story (Propp, 1971); iii) attending to - from a performative standpoint - how the context and the circumstances in which it is told condition the specific meaning of each story (Bamberg, 2012).

In this paper we will mainly attend to narrative as a cognitive mode, that is, and following Bruner (2004), Polkinghorne (1988), and Ricoeur $(1978,2004)$, as a psychological modality of processing information that allows us to organize experience in a particular temporal way. We are interested in narrative productions, accounts, and stories as a discourse genre and as an object, since they might be the expression, as we believe, of this mode of cognitive functioning. (In this study, our main interest focuses on the client's autobiographical narratives that emerge in the context of her psychotherapeutic process.)

In regard to narrative as a method, we will focus on the possibilities provided by narrative analysis for the study of autobiographical accounts at the micro- and macrostructural levels. (The performative plane will be left out, as it is beyond the scope of the present study.)

We use the term autobiographical narrative to refer to the set of personal narratives and microaccounts used by a subject to describe and characterize a series of relevant and significant episodes in his or her own life. In order to speak of an autobiographical narrative, these narratives and microaccounts will need to be articulated in a timeline and within a larger account: that of the protagonist's life. The different facts described in these microaccounts will also need to involve a connotation and have some kind of impact or relevance for the subject. The narrative must finally serve to account for the main character's development or evolution over a certain period of time. (By autobiographical account we mean this or that textual narrative which has emerged as an actual production that can be used as an analysis document on which the reconstruction of each autobiographical narrative can be based.)

\section{Autobiographical narrative and personal identity}

Conceptualizations linking autobiographical narratives with the sense of self or personal identity have been developed from different approaches and lines of theory sharing a narrative orientation. According to Ricoeur (2004), personal identity emerges from our competences to narrate stories about ourselves. Ricoeur (1996) proposes narrative as the action through which personal identity might be configured narratively (this occurs to the extent that the events in the biography intertwine to give rise to the plot of the story itself). In this author's view, identity might take shape on the basis of those stories themselves. This leads him to state that personal identity might essentially be a narrative identity (Ricoeur, 2004).

According to Bruner $(2003,2004)$, the self might be a product of our narrative skills to construct an autobiographical account that incorporates our memories, fantasies, and projects into a coherent plot. He states that our sense of congruence - but, above all, our experience of permanence in time, both as subjects and agents - might depend on this. In other words, the ego might be a product of subjects developing narratives about who they are, where personal identity becomes a central element that is made possible by - but which in turn gives rise to - a narrative construction (Duero, 2006). Therefore, our narratives become a matrix for the organization of personal meanings; the ability to sequentialize experiential information in the form of accounts and plots linked and made possible by a theme might seem key to their development (Bruner, 2010).

For Botella and Gámiz (2011), identity might be both the product and the process of self-narrative construction. According to these authors, everything we include in or exclude from our own narratives - and the way in which 
we do it - might constitute our own identity, just as the content of our life stories does. As they point out, this is the reason why identity becomes authorship in terms of the choice we make, among other aspects, of the main topics and events around which the story is organized, the characters in the story, and the prominence we give them.

\section{Analytical dimensions of self-narratives and autobiographical accounts}

Research into autobiographical narratives has attended to the mediating role that the dimensions and the modes of narrative construction might play in the development of personal meanings, conditioning a story's aspects of form and content (which, in turn, affect the subject's identity level). These perspectives have also attended to other factors that might contribute to the configuration of self-narratives, such as the client's psychopathological aspects or the particular characteristics of his or her life experiences.

According to Gonçalves (2002), people organize their personal meanings on the basis of a narrative matrix. Its architecture may be conditioned by three dimensions: i) the structure, that is, the relatively coherent way in which the different actions and events are unified as part of a dynamic and significant totality within an autobiographical narrative; ii) the narrative process, which refers to the quality, variety, and complexity of the narrative production in sensory, emotional, and cognitive terms; and iii) the narrative content, which becomes evident in the richness and multiplicity of themes, events, scenarios, and characters that are part of the account (Gonçalves, 2002; Botella \& Gámiz, 2011).

The analysis of these dimensions might have served to study the personal narratives of different clinical populations and permitted, among other things, the identification of certain typical narrative configurations in people with a diagnosis of mental disorder. Gonçalves (1995, 2002) uses the expression prototypical narratives to refer to the specific forms of cognitive organization and meaning-construction processes that can be identified and associated with different psychopathological symptoms. By attending to topical and structural narrative levels, Gonçalves's team succeeded in identifying prototypical narratives of depression (Sousa \& Cruz, 2008), agoraphobia (Gonçalves, Henriques, Alves, \& Soares, 2002), anorexia (Henriques, Machado, \& Gonçalves, 2002; Machado et al., 2005), drug-addiction, and alcoholism (Fernandes \& Gonçalves, 1997). Each disorder might be associated with a typical form of narrative construction that might function as a script, giving stability and coherence to the client's experience. These narratives, however, might also prove limiting, as they might impose restrictions preventing the client from recognizing the multifaceted aspects of reality, thus locking him or her up in a set of thematic invariants (Gonçalves, 2002) that might not favor his or her adjustment and adaptation.

According to Dimaggio and Semerari (2001), an effec- tive and well-constructed narrative allows a person to reach a relatively integrated perception of reality and of him or herself. One of the structural components that define the effectiveness of a story is its degree of coherence. When a narrative is coherent, it provides us with both an orientation to contextualize events and an affective language to highlight relevant elements; it includes some reflection with regard to the reason why we are told a story, etc. In contrast, disruptive narratives might make it difficult for one to arrive at a complex and coherent perspective of the world and of oneself (Baerger \& McAdams, 1999). In that sense, different studies suggest that low levels of narrative coherence might be associated with poor mental health (Adler, Wagner, \& McAdams, 2007; Neimeyer \& Raskin, 2000). Adler, Chin, Kilisetty, and Oltmanns (2012), for example, have described disruptive patterns in the narratives of borderline clients; these authors observed that these persons had particular ways of describing the experience of their own agency and the feeling of communion that characterize these types of stories. Lysaker and Lysaker (2001) identified three types of narrative incoherences in clients with schizophrenia: barren, cacophonous, and monologue narratives. On the other hand, different studies seem to show that the narratives of traumatic experiences that have not been properly elaborated are less coherent and more disorganized than stories that involve elaboration (Neimeyer \& Stewart, 1996; Capella, 2017).

Duero and Limón Arce (2007) have studied the organization of autobiographical accounts, trying to identify their fundamental components. Among other things, they have tried to recognize different narrative strategies. These authors understand narrative strategies as the type of discursive resource according to which each narrator organizes the account structurally and functionally, demarcating its plot and its composition as well as ensuring its coherence and openness. Based on their analyses, this team has recognized two narrative dimensions: a thematic-structural dimension and a functional dimension. The analysis of narrative structures has attended to an account's composition, that is, to its plot, as well as to the way in which the characters are represented in terms of traits, subjectivity, and agency (Duero, 2010; Duero \& Córdoba, 2016). Within the functional dimension, these authors identify the concluding activity (which refers to what - through their narrative - people seem to invite us to think about them, other people, and the world) and support functions (which include those additions made to the narrative in order to amalgamate and prop up the concluding activity). A higher or lower level of coherence of a narrative may depend on the richness and balance between these functions. Following Gergen's proposal (1994) and taking composition into consideration, these authors have identified different types of accounts: progressive, regressive, stability, and stagnant narratives (see also Duero \& Córdoba, 2016; Duero \& Córdoba, 2017). In a complementary way, Soru and Duero (2011), Car- 
reras and Duero (2012), and Duero and Córdoba (2016) have identified story styles and typical narrative strategies in pathologies such as depression, anorexia nervosa, and anankastic personality disorder.

\section{Autobiographical narrative in the therapeutic process}

According to Avdi and Georgaca (2007), the central role played by narrative processes during psychotherapy might be an increasingly recognized premise by most theoretical orientations in this discipline.

From the standpoint of narrative approaches in psychotherapy, psychological difficulties are seen as the reflection of situations where the client's personal self-narrative does not adequately represent the vital aspects of one's experience (Anderson, 1997). Therapy is conceptualized as a repair process through which autobiographical narratives of a dysfunctional or problematic nature are reconstructed with a view to making them more coherent, complex, multifaceted, and inclusive of past experiences.

From a constructivist-narrative perspective in psychotherapy, Botella and Gámiz (2011) state that psychological problems might be inseparable from the construction of identity narratives. Many of the problems and disorders that emerge during therapy might share the subjective experience of intelligibility of one's story and of loss of the sense of agency. Consequently, subjects might end up, among other things, assuming a position of authorial powerlessness (p. 253) with regard to their own self-narrative. This might be expressed in a diminished ability to rewrite a different script about one's story.

Anderson and Goolishian (1992) highlight the importance of some narrative factors in the construction of therapeutic change; in these authors' view, therapy is a dialogic relationship where new narratives opposed to the official story are rewritten. They point out that the transformational power of narratives might lie in their ability to re-tell or rerelate the events of our lives in the context of new and different meaning. In this area, narratives are considered the main vehicle through which clients construct meaning during this process (Gonçalves \& Machado, 1999); psychotherapy is considered a scenario for the identification, construction, and deconstruction of narratives (Gonçalves, 1995 , p. 104). In other words, therapy might be equated with a collaborative dialogue aimed at transforming the client's identity narratives (Botella \& Gámiz, 2011). The assumption here is that the process of narrating an autobiographical story might contribute, on the one hand, to keep the core aspects of one's own identity; on the other hand, it might help to smooth (Spence, 1986) the contradictions that emerge with regard to those alternative versions which affect the client's sense of internal coherence (Potter, 1996).

Mahoney (2005) observes that, when clients come to therapy, they interpret their life stories with negative characterizations of themselves. In addition, they do not perceive themselves as active or free agents. Their initial interpretations tend to present characters and problems in a polarized way. According to this author, therapeutic change might be conceived as a narrative reconstruction of personal meanings, where the client is helped to get back his or her authorship and rewrite different and fuller dimensions of his or her life. This rewriting might lead to transformations of the ways in which the client sees him or herself, others, the past, the future, etc. These changes, according to Mahoney, might be facilitated by certain characteristics likely to be observed in clients' autobiographical narratives, such as an increase in the complexity of characters (especially the self [as a main character]) and of the storyline; a change in emphasis, from the past, toward current events and future possibilities, and a change toward a more positive and active interpretation of the self (Mahoney, 2005, p. 158).

\section{Analysis of self-narratives in psychotherapy}

The study of autobiographical narratives in the field of psychotherapy has linked aspects of the process and therapeutic result with changes in clients' self-narratives. Over the past few years, different strategies of narrative analysis have been developed. They have incorporated quantitative, qualitative, and mixed elements to study autobiographical narratives and their connection with psychotherapy. These proposals have focused differentially on several dimensions of autobiographical narrative construction (structure, process, and content). By way of examples, among the mixed orientation strategies, the following can be highlighted: the Narrative Process Coding Scheme (Angus \& Hardtke, 1994; Angus, Levitt, \& Hardtke, 1999); the analysis package made up by the Narrative Structural Coherence Coding System (NSCCS) (Gonçalves, Henriques, \& Cardoso, 2001); the Process Complexity Coding System (PCCS) (Gonçalves, Henriques, Alves, \& Rocha, 2001); the Content Multiplicity Coding System (CMCS) (Gonçalves, Henriques, Soares, \& Monteiro, 2001); or similar instruments such as the Narrative Assessment Grid (NA-Grid) (Botella, 2008; Botella \& Gámiz, 2011), etc. On the other hand, we found the Innovative Moments Coding System (IMCS) (Gonçalves, Méndes, Ribeiro, Angus, \& Greenberg, 2010).

Based on this type of analysis systems, some authors have concluded that a successful therapy was associated with a greater complexity in the client's narrative process (Angus \& Hardtke, 1994). This type of studies made it possible to identify narrative modes in clients' self-narratives that might be associated with the successful course of therapy (e.g., reflective modes over internal and external modes).

In other research studies using the NA-Grid and the above-mentioned coding systems for the analysis of narrative process, structure, and content (NSCCS, PCCS, and CMCS), respectively, clients' self-narratives have been assessed during the initial, middle, and final stages of the therapeutic process by comparing cases of poor and good therapeutic results. These studies have shown a greater 
multiplicity of content, a greater structural narrative coherence, and a greater complexity of the narrative process in clients' self-narratives after a successful therapeutic process (Botella \& Cutura, 2015; Moreira, Beutler, \& Gonçalves, 2008).

In another research line, Gonçalves and his team have used the IMCS to study the different moments in the therapeutic process, attending to those segments when clients show signs of change (innovative moments) or, in contrast, ambivalence to change (ambivalence) with regard to the content of their problematic self-narrative. These authors have linked both instances to the global therapeutic outcome, depending on whether there is a prevalence of innovation and development of alternative contents, or rather a return of problematic self-narratives in the characteristics observed by researchers in clients' self-narratives (Gonçalves, Matos, \& Santos, 2009; Gonçalves \& Ribeiro, 2012; Gonçalves, Ribeiro, Mendes, Matos, \& Santos, 2011; Ribeiro, Gonçalves, Silva, Brás, \& Sousa, 2016; Ribeiro et al., 2014). In relation to the return of problematic self-narratives, the authors have attended to the analysis of different microstructural and thematic aspects, as well as semiotic aspects in clients' narratives. Their results seem to suggest significant associations between the characteristics of stories during one and the other type of episodes.

Despite the wide variety of methods described, for authors such as McLeod (2011) qualitative analysis remains a central contribution to narrative analysis because, among other things, this line of research makes it possible to capture complex and multifaceted aspects in a story, as well as the meanings at stake that emerge within the therapeutic context, which are beyond the scope of quantitative analysis. This author points out that this type of approach provides us with additional tools that are necessary for the study of self-narratives and their relation to change. He holds that changes in the structure and content of these stories serve as indicators of therapeutic change. In addition, he states that this type of analysis has the potential to generate new understandings of the process and outcome of therapy.

Following this line of research, Salvatore et al. (2006) have suggested that successful psychotherapy helps clients to overcome hierarchical disorganization, as well as overproduction of narratives. Empirical evidence seems to show that personal identity is modified during a process such as that of psychotherapy and that these transitions are associated with changes in autobiographical narratives themselves, as well as with a reorganization of the sense of one's own agency (Adler, 2012). Adler and McAdams (2007) found important changes in the ways in which clients defined their own agency in narrative terms after a successful therapeutic process. In addition to this, therapeutic change might be associated with a reconstruction of the problem for which they consulted the therapist - as a discrete entity, bounded in time and space. On the whole, stories at the end of the therapeutic process were more coherent than those at the beginning of treatment.

\section{Objective}

In this paper we will seek to describe, characterize and compare, based on a case study, the predominant narrative strategies used by a client with a diagnosis of depression in order to shape her autobiographical narratives in two clearly distinct moments of her psychotherapeutic process.

\section{Research question}

What are the predominant narrative strategies used by a client with depression to shape her autobiographical narratives at the beginning and end of a psychotherapeutic process?

\section{Materials and Methods}

\section{Data collection}

The study was carried out based on the data that the Millennium Institute for Depression and Personality Research (MIDAP) of Santiago, Chile, provided for our research in the context of one of the authors' doctoral thesis.

The case we analyzed is part of a sample of therapeutic process records, originally produced as part of Research Project No 1080136 by Chile's National System of Public Funds for Scientific and Technological Research (Fondecyt), approved in 2008. All the clients in the original sample had undergone a psychotherapeutic process supervised by the institution. The sessions had been recorded by audiovisual means and in writing under informed consent. Different theoretical approaches had been used for treatment (psychodynamic, cognitive, etc.). Subsequently, we chose a subsample of four cases from the original sample. All the clients in the subsample had been previously diagnosed with depression and had assessments indicating their clinical improvement as a result of the therapeutic process.

In the four cases, the stories that had emerged from the initial sessions of the therapeutic process were analyzed. In addition, an analysis was carried out of other segments of the process identified as stuck episodes and therapeutic change episodes, empirically derived from the theory of subjective change (Krause, 2005).

In order to write this paper, we chose one of those four cases. The selection criteria were, firstly, the richness of the analysis material in narrative terms; this client's narrative presented a degree of complexity and diversity in the use of narrative strategies that rendered it suitable to illustrate different aspects typical of the evolution of stories. On the other hand, the clarity in the expression of depression symptoms at a clinical level was taken into consideration.

For the case study, a preliminary analysis of sessions 1,10 , and 20 was carried out as part of the pilot applica- 
tion of the proposed analysis model. Next, the evolution was compared throughout the three sessions. Finally, the first and last sessions were selected because they illustrated changes in the stories. (The session in the middle stage of the treatment contained narrative strategies which were at a transition level in relation to those in the first and last sessions).

\section{Case description}

The client is an unmarried, 65-year-old adult woman with a diagnosis of depression who completed 20 sessions of psychodynamically-oriented psychotherapy. It should be noted that the client was undergoing pharmacological treatment for depression concurrently with psychotherapy. The diagnosis was confirmed by the Observation Guideline for the Diagnosis of Depressive Symptoms (Salvo, Cordes, \& Valdés, 2012). This was applied by trained assessors following the described procedure in at least two previous studies where this client's data were analyzed as part of a sample (Orellana, Cantizano, \& Valdés, 2017; Valdés \& Krause, 2015).

The measures of clinical improvement associated with the therapeutic process were previously obtained by applying the Outcome Questionnaire (OQ-45.2) (Von Bergen \& de la Parra, 2002). After the treatment, her scores showed a significant and sustained therapeutic improvement in time. Her initial score (session 1) on this questionnaire was 130, with 74 points on subjective distress, 33 points on interpersonal functioning, and 23 points on social role. Her final score was 108, with 62 points on subjective distress, 24 points on interpersonal functioning, and 22 points on social role. The score differences allow us to account for the significant improvement shown by the client after her therapeutic process.

For the analysis, the entire therapeutic process was videotaped with the informed consent of the participant. Subsequently, the transcription of the sessions was completed. The standards described by Mergenthaler and Gril (1996) were used for the transcription. The names and any data that may identify the client were modified. Finally, a complete analysis of the material selected for the study was carried out.

\section{Reason to consult}

The client had a college education and had worked as a freelance professional. She was retired at the time of her psychotherapeutic process (2008-2009). She had an adult adopted daughter, Mini, who was married with two children. Her reason for consulting were the feelings of distress, dejection, sadness, and emptiness that she had been experiencing for some time. She had had a suicide attempt a few months before the beginning of her treatment. During the first session, she referred to a conflictive bond with her daughter; she said that she assumed an overprotective role with Mini. Throughout the course of therapy, other topics of concern emerged: her usual feelings of guilt, her tendency to become overinvolved in her relationships with others, her fear of separations, and the way in which she avoided dealing with her own problems by taking care of other people's.

\section{Analytical approach and general procedure}

We start from an in-depth textual analysis of two psychotherapeutic sessions. This is an exploratory case-oriented study based on the phenomenological-narrative method (Duero \& Córdoba, 2017). The method is phenomenological as it is part of the detailed description of the different elements that make up the stories. The objective of this approach is to arrive at a comprehensive view of the ultimate meanings that emerge from the experiences described by clients (Ellenberger, 1967; Binswanger, 1956, 1961). The method is also narrative because it articulates a systematic methodology for the analysis of thematic-structural aspects, as well as the functions that prop up the story's coherence (Duero \& Limón Arce, 2007). The method used is part of the narrative analysis approach (Bernasconi, 2011; Riessman, 2008), which, in turn, might be part of narrative research methods and qualitative research methodologies (Capella, 2013). In the field of psychotherapy research, narrative analysis might be seeking to develop a new understanding of the way in which language constructs personal realities, assuming that subjects make sense of and communicate their experiences in the form of stories; on the other hand, the stories told by clients in this context may be considered a primary source of data (McLeod, 2011).

For the analysis, we have applied the procedure described by Duero and Limón Arce (2007). Taking the two main dimensions proposed by the authors - thematicstructural and functional - we have categorized and compared the narrative strategies predominantly used by the client during the first and last sessions of her psychotherapeutic process.

The data processing, especially coding tasks, was carried out using a qualitative analysis software, ATLAS.ti, as an auxiliary. We present the result of the complete analysis of both sessions. By way of examples, we have chosen to quote some excerpts that we consider especially illustrative of the most relevant results.

\section{Procedures}

A phenomenological-narrative analysis of the stories was carried out (Duero \& Limón Arce, 2007; Duero \& Córdoba, 2017). The general outline of the steps taken was as follows: i) thorough reading of the material (all the sessions in the therapeutic process (sessions 1 through 20) in a first unstructured exploratory approach to familiarize ourselves with it; ii) focused reading of sessions 1 and 20; iii) division of each text into thematic-narrative units (identification of differentiable topics in and through the client's speaking turns); iv) identification and analysis of the model's main dimensions and categories: iv.i) analysis of the composition 
and narrative structure, and iv.ii) analysis of narrative coherence (functions); v) both a phase of interpretive criteria matching and of intersubjective agreement between researchers; vi) final material analysis, where comprehensive hypotheses were proposed and both sessions (1 and 20) were interrelated and contrasted.

\section{Analytical dimensions and categories}

We carried out an analysis of the thematic-structural and functional dimensions of the client's autobiographical narrative in each of the two selected sessions. We have attended to the analysis of composition and coherence (Duero \& Limón Arce, 2007).

\section{Analysis of the composition and narrative structure}

i) In order to analyze the composition and the narrative structure, we firstly identified the main thematic nodes and the significant events of the story, that is, the topics together with the most important life events around which the account unfolds. (Significant events represent turning points or identifiable milestones within the story, generally based on the protagonist's actions. These may include descriptions such as "that time when I moved to a new house", "that time when I was unfaithful", "that occasion when I hit my child", "when I got sick", "when I divorced", etc. It is possible to draw a timeline and trace an outline of the storyline or plot by identifying significant events; Soru \& Duero, 2011; Carreras \& Duero, 2012)

ii) In relation to the plot, we differentiated: the framework or initial situation of the account, which is defined by the way in which the author of the story characterizes what he or she considers normal or habitual (typical situations). On the other hand, we recognized atypical or conflict and change situations, as well as the denouement and the consequence that the end of the story implies for the protagonist. (The denouement tells us about the resolution of each story and each microaccount; it may be overcoming an obstacle, finding something one had lost, etc. It will always depend on the set of motivations guiding the main character's actions and expectations. The consequence, on the other hand, will refer to how the protagonist becomes involved in the denouement and what implications it has for him or her in moral, affective, or pragmatic terms; Duero \& Córdoba, 2017)

iii) We also looked at the way in which the main character and other significant characters are characterized. We identified: iii.i) the characters' representation, that is, the author's definitions and characterizations about him or herself and others, which include comments on more or less typical or significant traits, qualities, attitudes, and actions; iii.ii) subjectivation, that is, expressions referring to experiences or alluding to the psychological background of motives and reasons that justify their actions and their expectations; iii.iii) agential attitude and actantial role (Greimas, 1966). Agency refers to the more or less active disposition adopted by the protagonist and the other characters in the story. Actantial attitude refers to the role that the protagonist and the other characters adopt in relation to one another. Here we basically identified the functions of actant-donor and patient-recipient.

\section{Analysis of the narrative coherence (functions)}

i) The coherence of a story depends mainly on the way in which cardinal and catalytic functions are linked together. Thus, it depends on how explicit and successful the articulation among the different moments and levels of the account is (Barthes, 1991). As we stated earlier, according to Duero and Limón Arce (2007), the coherence of an account may be ensured, at a primary level, by a kind of counterpoint between the concluding activity of the narrative and what they call supporting functions. The concluding activity may summarize the set of assumptions that the author wishes to convey about him or herself, about others, about the world, and about what has happened. It is based on a series of definitions and characterizations made by the author and protagonist about him or herself and the world. However, the concluding activity must also be inferred, in part, from what Duero and Limón Arce call support functions. (The analysis of the story's functional level, in its different stages, requires coding tasks of the analysis units. This makes it possible for the researcher to assign different categories to the analysis units according to his or her interpretive criteria)

ii) Types of support functions: every story begins with a predicate or a set of predicates that introduce a topic and define a situation. Sometimes these initial predicates are grouped with others, which are distributed in the account, giving rise to what we call proconcluding comments (PCCs) and proconcluding metacomments (PCMs). A PCC and a PCM are usually statements through which the narrator defines the protagonist, significant others, and the world. We refer to a predicate as a PCC if an assertion of an ontological or essentialist (dogmatic) nature is presented, whereas we refer to it as a PCM if a comment with a self-questioning tone, opinion, or reflection (doxatic) is made about how things could be understood or looked at. As we were saying, initial predicates can be followed by other sets of predicates that develop them by expanding the topic and articulating it with other parts of the account (in a theme-rheme sequence); however, interruptions may be made and new topics introduced as well. While in the first case the different propositions tend to amalgamate, the continuous introduction of new topics (i.e., the absence of catalysis) blurs the possibility of shaping a plot, as well as of reaching certain concluding activity (Table 1)

iii) Among the main support functions, Duero and Limón Arce (2007; see also Duero \& Córdoba, 2017) recog- 
nize: iii.i) Remarks (RMKs): it is useful here to differentiate amplifications or specifications, with which more information or details are provided to help specify a topic introduced; clarifications, with which some particularity - intended to be visible - is made more obvious and intelligible; illustrations and exemplifications, which consist of the anecdotal presentation of cases or situations to support what is said; iii.ii) Within genic-causal schemes (GCSs), we identified: explanations, which are attempts to account for something in terms of facts or objective factors: "Why did a particular event or action happen or take place?"; interpretations, which are attempts to answer the previous question in terms of understanding, and ascribing to the character a hypothetical set of motives and reasons; justifications, which have a persuasive role and will answer the questions "Why am I saying this?", "Why am I doing this?", or "Why did I do this?" Our assumption is that when the concluding activity is propped up by a balanced system of support functions, the coherence and organization that an account seems to show are greater; whereas accounts with poor support appear to us as fragmentary, disconnected, and generally incoherent or dispersed (Table 1)

iv) PCCs, PCMs, and the rest of the support functions are enunciated by different types of predicates; these are as follows: Ontological and Existential-of-State Predicate (OEP), which characterizes a situation in terms of permanence; Deontological Predicate (DP), which defines how things should be; Circumstantial and Frequentative Predicate (CFP), which alludes either to specific actions and events situated in time and space or to descriptions of the frequencies with which an action or behavior has taken place; Prophetic or Possibility Predicate (PPP), which refers to things that might happen, are expected to happen, or might have happened; Existential-of-Becoming Predicate (EBP), which refers to a change process in the character's life; Existential-of-Decision Predicate (EDP), which highlights a position taken regarding a situation; Subjectivating Predicate (SP), that is, an expression where mental verbs are used that refers to experiences and internal subjective states; Interpretive Predicate (IP), where underlying mental states are inferred in order to account for behaviors or attitudes; Evaluative Predicate (EP), which expresses a personal consideration or assessment of a character or situation. In this regard, it should be noted that some preliminary analyses seem to indicate that OEPs commonly abound in accounts with numerous PCCs. Generally, they bring with it a tone of objectification to the narrative. The abundance of CFPs over other predicates is usually found in accounts with little concluding activity. SPS, IPS, and $E P s$, along with EBPs and EDPs, tend to be present in PCMs. They help both to give the story coherence and to favor openness, as well as a heterodox and relative point of view (the latter must obviously be relativized, since everything will depend on how the different types of predicates are expressed in context (Table 1).

\section{Summary of the main steps of the procedure}

The analysis was carried out by following the steps below (Table 2):

Table 1. List of the main abbreviations used for codes.

\begin{tabular}{|c|c|}
\hline Concluding activity & [Proconcluding Comments (PCCs)] \\
\hline & [Proconcluding Metacomments (PCMs)] \\
\hline Support functions & $\begin{array}{l}{[\text { Remarks }(\mathrm{RMKs})] \text { : amplifications or specifica- }} \\
\text { tions; clarifications; illustrations and exemplifi- } \\
\text { cations } \\
{[\text { Genic-Causal Schemes (GCSs)]: explanations, }} \\
\text { interpretations, justifications }\end{array}$ \\
\hline Predicates & $\begin{array}{l}{[\text { Ontological and Existential-of-State Predicate }} \\
(\mathrm{OEP})] \\
{[\text { Deontological Predicate }(\mathrm{DP})]} \\
{[\text { Circumstantial and Frequentative Predicate }} \\
(\mathrm{CFP})] \\
{[\text { Prophetic or Possibility Predicate }(\mathrm{PPP})]} \\
{[\text { Existential-of-Becoming Predicate }(\mathrm{EBP})]} \\
{[\text { Existential-of-Decision Predicate }(\mathrm{EDP})]} \\
{[\text { Subjectivating Predicate }(\mathrm{SP})]} \\
{[\text { Interpretive Predicate }(\mathrm{IP})]} \\
{[\text { Evaluative Predicate }(\mathrm{EP})]}\end{array}$ \\
\hline
\end{tabular}

Table 2. Steps for the analysis within the analytical dimensions and categories.

i) Identification of the main thematic nodes;

Analysis of the composition and narrative structure

ii) Identification of significant life events;

iii) Identification of the framework;

iv) Identification of the denouement and the consequence;

v) Description of the character's characterization;

vi) Characterization of significant others

vii) Identification of the types of support functions (coding tasks);

Analysis of the narrative coherence

vii.i) Identification of PCCs and PCMs (coding tasks);

vii.ii) Identification of other support functions (i.e., the different types of RMKs and GCSs) (coding tasks);

viii) Identification of types of predicates (coding tasks);

ix) Identification of the concluding activity;

$\mathrm{x})$ Plot synopsis

PCCs, Proconcluding Comments; PCMs, Proconcluding Metacomments; RMKs, Remarks; GCSs, Genic-Causal Schemes. 
i) Identification of the main thematic nodes; ii) Identification of significant life events; iii) Identification of the framework; iv) Identification of the denouement and the consequence; v) Description of the character's characterization in terms of traits and behaviors, subjectivity, and agency-actancy; vi) Characterization of significant others; vii) Identification of the types of support functions; vii.i) Identification of PCCs and PCMs; vii.ii) Identification of other support functions (i.e., the different types of RMKs and GCSs; viii) Identification of types of predicates; ix) Analysis of the concluding activity: after a careful and comprehensive reading of the material, an attempt was made to identify the concluding activity; $\mathrm{x}$ ) Plot synopsis: taking into account the above and in keeping with point nine, we proceeded to outline a brief synopsis of the narrative's storyline and plot for each psychotherapy session.

\section{Results}

Detailed data analysis revealed an observable qualitative difference between the stories that emerged in both sessions. The thematic-structural analysis and the analysis of the narrative functions of the story in the last session showed a richer and more complex narrative than that in the first session. This was observed at the following levels.

Main Topics and Significant Events: The story shifts from references to significant others and descriptions of past events to mainly self-references and present events.

General Framework: Both the description of the conflict and how the protagonist places herself in the face of problems change, as well as the evaluation of the denouement and the consequences. A new way of positioning herself in relation to the future can be observed.

Characterization and Identity Anchoring: The protagonist's characterization shifts from being based on permanent traits to being based on subjective states. Greater self-reflection is observed, as well as a change in her agential attitude and her actantial position.

Characterization of Significant Others: During the last session, the other characters are subjectivized better; in addition, they are shown as having an active agency.

Plot and Storyline: The story in the first session is a progressive-regressive narrative. The story in the last session shows characteristics of a progressive narrative.

Concluding Activity: The concluding activity in the first session focuses on external events and on the behaviors of other characters. In the last session, a more selfreferential concluding activity is observed. This leads to a resignification of the problem.

Analysis of Support Functions: In the first session, there is a predominance of PCCs mainly propped up on OEPs. Therefore, situations and characters are defined in terms of more or less unmodifiable states. In the last session, many PCMs with EPs emerge. This suggests a greater reflective activity and greater openness in narrative terms.
There is a detail of the main findings regarding each of these points below.

\section{Synopsis}

In order to orient the reader, a synopsis of the client's story in sessions 1 and 20 is presented below. The synopsis was based on the identification of: i) the main topics; ii) the sequence of the main significant events; iii) the concluding activity.

Based on the client's own narrative, the synopsis of the story in the first session could be the following:

$X$ was a devoted and eager mother who had made every effort to raise her adopted daughter. Her daughter was ungrateful, violent, irresponsible, and disrespectful. She herself caused her own misfortune. The mother suffered a lot because of this. She felt that she could not change her daughter. But she could not stop worrying about her and could not see her suffer. So she tried to help her. But the more she gave her, the more frustration, guilt, and sadness she felt. Over time this led $X$ to a desperate situation.

During the last session, the following is added to the narrative above:

Over time X realized how she herself was involved in the generation and maintenance of this problematic relationship with her daughter and began to contemplate possibilities of change.

\section{Main topics}

The central topic in sessions 1 and 20 is the same, although it is characterized and analyzed from different standpoints. In both cases, it is the protagonist's conflictive bond with her adopted daughter, Mini. In front of Mini, she behaves as a donor-giver. In both interviews the daughter is described as impulsive and as having behavioral problems. An asymmetric relationship without reciprocity is presented. The daughter appears as a receiver-ungrateful person. However, in session 1, the focus is on the problems presented by Mini, while in session 20 the client focuses, at least in part, on her own participation and responsibility in the problem, manifesting a more open attitude to change sometimes. In session 20, a new topic also appears: the fear and distress experienced by the client when she has to say goodbye. This leads her to review her way of bonding with other people and her difficulty in accepting help and trusting others.

\section{Significant events}

During session 1 the client tells the story of the problem. She elaborates on different relevant events in her and her daughter's biographies. The main ones are as follows: Mini's adoption: "I took care of her when she was born", "She is my stepbrother's love child"; partial readoption: The protagonist is again partially in charge of Mini after a time of separation when Mini returns to her biological 
mother: "So she arrived when she was 12 or 13 years old and began taking her stuff to my house"; behavioral problems/Mini's pregnancy: "We got to the issue of Mini's schooling with much difficulty, you know", "I try to get her to keep going to school"; "She didn't go to school in the third semester", "She became pregnant before that"; wedding, separation, and Mini's and the protagonist's suicide attempts. Then Mini separates from her partner and tries to commit suicide. This leads to the protagonist's current state of demoralization and distress. Before starting this therapeutic process, she also had a suicide attempt.

In session 20, an allusion to the protagonist's own suicide attempt appears as the only relevant significant event. She refers to what that meant and still means to her within the current framework. In addition, other minor facts are narrated - almost all current ones - whose function is to illustrate the relational problem, which still persists, albeit with certain changes.

\section{General framework}

The story's framework emerges entirely during session 1. It is a typical situation of malaise that remains unchanged over the years and that extends until it becomes mixed up with the crux of the problem; it begins with Mini's adoption and drifts along around her in the protagonist's attempt to save her. A series of OEPs frame and shape the story, giving the context ("Let's say that, besides, my whole life has been like a tragedy"), as well as the protagonist ("I always put myself in the back burner; I draw strength from weakness, I am very strong"), more or less permanent objective characteristics. The protagonist positions herself as a hero, a fighter who has to face adversity. This is reinforced by how she describes herself in the past prior to Mini's adoption: "I had no childhood", "I had no guides", "I did not have a mother's role model", "My only way out was to develop my intellect". Based on her determination and effort, she manages to overcome the initial situation of deprivation and becomes an "overwhelming leader"; "I earned a lot of money", "I was an advisor", "I earned my place". So far, this has been a progressive account, one of a heroic kind. But during adulthood there is a typical situation of instability that precedes the current conflict and makes the story regressive. There are also, as heretofore, adverse conditions. The difference is that the protagonist cannot sustain, despite her determination, her place as an efficient hero. She says, "Life gives me this little girl I didn't make", "I took care of her". Mini's characterization is based on traits and, above all, negative behaviors: "She seemed to be cast adrift", "She was self-destructive". Mini's biological mother was "out of all proportion", which gave the girl no support. "When she was eight, she was brainwashed and put into a sect". The protagonist manages to rescue her. "She lived with me from that moment on". That is when problems exacerbate because Mini “didn't want to assume roles". Thus, we arrive at the present, when Mini "has become a young girl" who "controls my life"; she is "incapable of making her own decisions". The protagonist concludes: now "I'm alone in the most absolute loneliness", "I've destroyed my whole family", "Nobody helps me".

In session 20, she mainly refers to the current framework, which becomes mixed up with the crux of the problem. The current situation of instability is described, which spans all the spheres of the protagonist's life. But as we will soon see, there is, however, an attempt to project herself toward a different place and look at reality from constructive self-criticism.

\section{Crux}

During interview 1, the main problem lies in relational difficulties and Mini's maladjustment. Mini's and the protagonist's suicide attempts come to crown, as a denouement, the conflict situation, now giving the narrative a tragic tone. When interview 20 is carried out, the problem envisages the responsibility of the protagonist herself in the situation. Here she outlines some hypotheses about the deeper nature of the conflict.

\section{Denouement}

Despite her efforts, the protagonist failed in her attempt to regain control of the family. Mini tries to commit suicide. So "the whole world collapsed". Then the protagonist herself commits a suicide attempt. "I called her and told her I want to die," "I'm going to die, I'm going to kill myself," "I can't stand this situation anymore." Now, in the present, she says, "I want to live and I don't want to live," "I think my life is chaos," "I'm tired of carrying this responsibility." Thus, we can see that we are moving from a progressive to a regressive narrative with tragic-dramatic connotations.

In interview 20, the denouement seems to open a new prospection. At the point of both suicide attempts, the protagonist problematizes her way of relating to Mini and other people; she also recognizes her difficulty in separating and tolerating distance and reviews her own difficulty in asking for and receiving help.

\section{Characterization and identity anchoring}

In session 1, the protagonist tends to characterize herself on the basis of traits and states through the use of OEPs. She appears both as a strong ("I tend to be a protective mother," "I'm always sort of very responsible," "I'm like a mother hen," "I draw strength from weakness") and a weakened figure ("I don't indulge myself," "I always put myself in the back burner," "I'm alone in the most absolute loneliness," "The only security I have is me").

The characterization based on actions is done by means of CFPs and it is poorer. She mainly refers to agency and actantial traits such as behaviors that involve effort or sacrifice or that denote giving, supporting, or caring for others. In relation to the first categories, she says, 
"I practically didn't go to school and they gave me special exams and I passed them," "I took advantage of every scholarship available there was," "I did all sorts of things." With regard to the other two categories, she comments, "When I was eight years old, I took care of my brothers"; "I filled Mini's pantry," "I bought her a house," "I gave her my car"; "I supported her boyfriend financially," "I trained him." Next, the current period of frustration and malaise in which she feels "emptied" arrives. So "first, I cut myself" and then "I took a lot of pills."

On the subjectivation plane, there are multiple SPs, but almost all of them have negative content or valence: "I said I hate you," "How long are you going to make me suffer?," "I feel guilty," "I ask them Don't make me suffer anymore," "That hurts me," "I can't stand seeing her," "I'm tired of carrying this responsibility." There are very few IPs referring to herself and some EDPs connoting intention (but no accomplishment), in addition to obligation, effort, and annoyance: "I was trying to give her [something]," "I try to get her to keep going to school," "I want to live and I don't want to live."

There is a variety of PCCs built on the basis of EPs with negative valence: "When I criticize myself, I do it trying to pretend I'm hurt, as if I don't deserve it," "I think my life is chaos," "I'm doing things indicating that I don't want to live." There are also a few PCMs built on the basis of reflective EPs: "I'm falling into the same trap of not indulging myself, of not worrying about myself," "I realized many things, but I'm here, hey!, doing the same all over again." Finally, there are few PPPs showing a rather vague view of the future, when she says, for example, "I think that [if the problem were solved] I'd do many things."

As we said earlier, at the level of agency, the protagonist apparently positions herself actively, especially in the past. However, it is rather an agency of frustrated intentions and concrete actions that entail a feeling of inefficacy. During a first stage in her life, she "gets" and "accomplishes" things, albeit rather out of necessity than her own desire or motivation. During the second stage, despite her efforts, she "fails." It is always about actions aimed at generating responses in others: "I'm going to give you such and such," "I'm going to help them," "I was going to come here trying to support her." That is, the protagonist does according to what others need, but, personally, she does not want or wish anything in a positive way. In the present, there is an agency tending to passivity: "I don't go out," "I sleep," "I stay in my shell"; now "I hand over responsibility to them [doctors]."

Unlike in session 1, in session 20 there is comparatively less characterization based on traits and OEPs on the part of the protagonist. There are also few references to concrete behaviors on her part. However, on the subjectivation plane, SPs predominate (although there is a prevalence of negative content or valence), which suggests a greater personal involvement, as well as the recognition of her own emotions in the present. While referring to the end of the therapy, she says, for example: "It'd be clearer to me, I wouldn't be feeling sad to say goodbye," "There's anger because there's sadness, because there's abandonment," "I'm terribly afraid of saying goodbye." There is also a more frequent use of IPs ("There's a terrible non-acceptance on my part," "I'm projecting what I need onto you") and EPs (while referring to her relationship with Mini, she says, "I always fall into the same trap, into the same hole," "I have a clear conscience that it was me who created part of this problem," "How painful it is to know one is doing that instead of trying to find a healthy way out"), all of which suggest reflection and selfobservation. Finally, there are some PPPs and EDPs expressing a more defined and concrete prospection; for example, she says, "In the future I hope to finish the pending tasks"; she speaks about some projects. In addition, referring to her previous suicide attempt, she says, "It's like I'm meant to be in this life" (and not to die); eventually, she admits, "I'm also capable of asking for help." Finally, at the level of agency, there is a less acting and a more reflective one. There is an attempt to review both the basis on which she is acting and her own actantial role as a giver: "I though that if I fell - I believed myself to be the support - everything was going to collapse and it wasn't like that and it was painful and pleasant; it was painful because I had the idea of being so important."

\section{Significant others}

During session 1, the main significant figure is Mini, her daughter. (There are also brief references to Mini's biological mother, Mini's husband, Josefa, her granddaughter, and the "rest of the family.") Mini's traits are defined by means of scarce OEPs. The rest of the characterization is almost exclusively based on CFPs referring to actions and specific events. The abundant use of CFPs may be related, precisely, to an attempt to describe the situation and receive help in order to sort it out and classify it. This matches a concluding activity that is sometimes contradictory, where Mini is almost always shown as a weakened figure. Mini is a "young girl" who "doesn't want to assume roles" and "goes mad." At the same time, she is "someone who can't [do things]," "someone weak," conditioned by her genetics and her life history. The latter, which reflects an objectivating characterization of the other, is summarized in the following PCC: "I had found a stone and found it beautiful and polished it, but a stone does not stop being a stone."

With regard to subjectivation, there are relatively few SPs and IPs referring to Mini (most of them are self-referential and have negative content): "I didn't matter to her," "She tells me that she can't be with me, that she doesn't feel capable," "She looked at me like saying what time are you going to die," "She was trying to beat me."

At the level of agency, Mini appears as having a passive and helpless role: "She does as I tell her and in the end she blames me," "She is 31 years old and still finan- 
cially dependent on me," "If Mini could make a life for herself - right or wrong - but far away." On the actantial plane, the daughter assumes a receptive and dependent role, that of a demanding and needy figure: "She doesn't earn [money]," "She has always depended on me." At the same time, Mini is a manipulative and absorbing figure: "That's how she begins, manipulatively, to stay in my house in order to create conflict"; "She sent word to me saying, I've already forgotten you, I control my own life." Her behavior is always unpredictable, impulsive and inexplicable, in terms of motives and reasons: "She went mad spending [money]."

Something that caught our attention during the analysis of session 20 is that reference to significant others decreases. The client focuses much more on herself. Correspondingly, there are few OEPs (most referring to Mini and some others to close relatives). Some of them appear associated with PCCs and with GCSs based on EPs, by means of which an attempt is made to give closure to the problem, enabling a conclusion. There is also a lower use of CFPs and less reference to specific behaviors, which might be indicating that there has already been a work of elaboration (abstraction and synthesis) on the problem. On the other hand, some of these references allude to positive aspects of Mini and even of other close people. She says, "Mini was by my side; she was fighting"; "She told me, We're going to get ahead"; "If we're together, we can eat stale bread." With regard to the family, she comments, "They've seen me very vulnerable and fragile and nobody has censored me; and I thought it' $\mathrm{d}$ be the other way around." The latter seems to suggest a greater perspectivism. Comparatively, there are more and more complex - EPs and IPs, which seems to suggest a qualitatively different assessment of the situation: referring to Mini, she says, "I don't know when she's manipulating me," "I doubt whether she loves me or doesn't love me." In addition, some hopeful PPPs appear: "It's a load of little windows; she knows someday I'll find the answer," "Someday my little watch will work so that I can get ready for the round in advance, you know what I mean?"

At the level of agency, an attempt is now being made to re-agentialize and hold others responsible in a healthy way, as well as to review the respective actantial roles. With regard to Mini, she says, "I ask myself, Where is she standing?"; "I don't know why she can't find her bearings"; finally, "I think one day she'll realize."

\section{Plot and storyline}

Session 1 presents a story of struggle and effort with a denouement of failure. She herself describes her story by saying, "My life has been like a tragedy." The protagonist positions herself as a hero, but she is a hero who has failed. It is a progressive narrative during a distant stage in her life and, for some time now, a regressive one of a tragic kind.
Session 20 focuses more on the present and on the protagonist's attitude with regard to her story and herself. New topics appear, including, for example, activities and projects that she enjoyed in the past: "I used to knit and do embroidery," "I embroidered kitchen towels," "I used to put some figures on them." A prospection that gives the narrative some progressive notes begins to open.

\section{Concluding activity}

The concluding activity in session 1 clearly emerges from some PCCs (more or less supported by RMKs and GCSs). The protagonist seems to be stating, "My life has been a tragedy. I've been conditioned by fatality. I've been there and I'm there for others, but nobody is there for me. I've gone the extra mile and I'm alone."

The concluding activity in session 20 points to a process of self-referencing and resignification of the problem. The protagonist recognizes her difficulty in trusting others and receiving help, as well as her need to take a step back to see the positive aspects of situations. She says, "I've felt forced to admit that I'm loved," but "I kind of tend to reject that and continue not believing it"; reality "is showing me that I'm loved, sometimes by people I had no clue about," "I feel I don't deserve to be loved." With regard to the therapy, she says, "There was a lot of progress, many achievements" but "I have to calm down to see them." She even recognizes that some of her ways of functioning are pervasive and extend beyond her problem with Mini: "As to Mini, let's leave her out because I'm the same with everyone."

\section{Analysis of support functions}

In session 1, several PCCs and very few PCMs can be observed. By means of OEPs, she tends to define the situation, others, and herself in terms of unmodifiable states. In addition to PCCs, there are GCSs (interpretations, justifications, and, especially, explanations) that seem to give closure to the story and justify the current state. For example, referring to her daughter, she says, "She was selfdestructive; she was destructive: typical of an abandoned child"; referring to the child's biological mother, she says, "She was never taught to be a mother," "She was also abandoned," so "the story is repeated." She also justifies her own actions, for example, her attitude as a caregiver with regard to this mother and her daughter, alleging reasons with pretense of objectivity: "being a protective mother of both because the mother is immature."

In session 20, on the other hand, a greater influx of evaluative PCCs and especially PCMs with reflective content is observed. The client seems to make an effort to self-observe. For example, she says, "I wonder whether here I'm putting on the same show Mini puts on at home," "I read it in a book and I find it so appropriate for me: I need a tragedy, a crisis to generate adrenaline and feel well," "And, you know, now the pains occur more often 
because I realize more often." On the other hand, there is also an effort to take advantage of the possibility of reflection to solve concrete problems: "After that, I thought (...) I'm going to calm down," "I'm going to think, I'm going to wait for the right moment to raise the issue." Finally, there is a more positive self-assessment of her own abilities to face the problem: "But, you know, I feel I have more resources."

Unlike in session 1, where the GCSs seem to trim and close aspects of the client's life reality, as they are fitted together with the PCMs, in session 20 the GCSs provide openness to the narrative, in addition to coherence and consistency. For example, while interpreting one of the conflict situations, she says, "I'm aware of that; suddenly, I get angry with her, but as we were saying the other day, it's like those love rages. That is, if there was no affection, I think there would be no frustration."

\section{Exemplifications}

Based on two excerpts taken from both sessions, the analysis of support functions is exemplified. Before each sentence, the type of function and the type of predicate have been written in block capitals.

\section{Session 1 excerpt}

PCC OEP "because I'm alone, in the most absolute loneliness". REMARK OEP “and not because I'm fragile and prefer to have company, but because I retired into seclusion" REMARK OEP "then, that is, I went into my shell..." REMARK CFP "It was after two very strong episodes occurred that, when I told the doctor (...), she moved super fast to get the appointment with Dr. Barros. That day I stayed at home with company and then the doctor started the treatment..." PCC OEP "Let's say my whole life has been like a Greek tragedy..." REMARK CFP "In June a rather dramatic episode occurred..." REMARK OEP "because I'd have to tell [him/her] I have a daughter who's not my daughter..." REMARK OEP "I took care of her when she was born because..." REMARK OEP "She is my stepbrother's love child..." REMARK OEP "So I retired when I was middle-aged...” JUSTIFICATION EDP followed by an OEP "I'd decided not to have children because I wasn't fit as a mother..." REMARK OEP/CFP "and just because life is like that sometimes, I was given this little girl that I didn't make." REMARK CFP "The first eight years of this little girl's life I did everything I could to support her, so that her mother would be there" GCS: EXPLANATION OEP/CFP "unfortunately, these stories come from way back; the mother was abandoned; she abandons this little girl."

This example illustrates some characteristic aspects of session 1 . The session focuses on the past in order to explain how the current problem was arrived at. The latter is only seen as a consequence of that antecedent situation.
The focus is primarily on the co-protagonist of the story. The concluding activity revolves around the idea that the latest events are simply the corollary of the fatal, tragic nature of the hand that fate has dealt the protagonist.

A coding of the excerpt can be presented as follows: $P C C$ OEP - REMARK OEP - REMARK OEP - REMARK CFP - PCC OEP - REMARK CFP - REMARK (AMPLIFICATION) OEP - REMARK OEP - REMARK OEP - REMARK OEP - JUSTIFICATION EDP - OEP - REMARK OEP/CFP - REMARK CFP GCS: EXPLANATION OEP/CFP.

As a whole, we observe that there are some PCCs and GCSs (which provide a superficial level of explanationjustification) supporting the concluding activity. The presence of numerous OEPs objectifies the situation. EBPs and EDPs are practically absent, as are PPPs. There are no SPs, IPs, or EPs contributing to subjectivation.

In terms of narrative richness, the account in session 1 presents too limited a focus; in other words, although it has an acceptable level of coherence (there are predicates introducing topics, there are PCCs, there are remarks, illustrations, GCSs with explanations and some interpretations and justifications), the account is thematically circumscribed to a reduced range of problems and situations and focuses on a single point of view.

\section{Session 20 excerpt}

PCM EP "That's not the solution; I think I'm projecting what I need onto you. That is, it's..." PCM EP "If only you knew how painful it is to know one is doing that instead of trying to find a healthy way out..." REMARK SP "Do you know what I mean? I'm paralyzed... and there are terrible days; there are days when I'm (...) I don't do anything..." INTERPRETATION IP "because there's no dramatic event for me to do something and react..." REMARK (ILLUSTRATION) CFP "you know, last time I was saying: but how is it possible if I was in bed five minutes ago and just because I received a call... I got fully dressed, got into the car, and left..." PCM EP "it's not necessary to try to find something so dramatic, that's what I think..." PCM: EP/SP "The thing is that's also my selfcriticism and my helplessness, my anger, because I'm lying there on the couch and I say, Why am I like that?, Why do I need a call?, Why can't I generate that desire?, do you know what I mean?" (...) PCC SP “Anyway, you don't know how much it bothers me to be compared to Mini!..." PCC EP "because, actually, I think at least I try and I don't hurt anybody and, secondly, I'm quite sincere when I express either affections or discomforts."

A coding of the excerpt can be presented as follows:

PCM EP - PCM EP - REMARK SP - INTERPRETATION IP - REMARK (ILLUSTRATION) CFP - PCM EP - PCM: EP/SP - PCC SP - PCC EP

This excerpt summarizes some of the main elements that emerge during session 20. The protagonist appears 
more self-centered and reflective. She shows an attitude of self-questioning and positions herself in the present. We observe PCCs and GCSs supporting the concluding activity. However, the presence of PCMs now contributes breadth and perspective to the conclusion. There is also a greater presence of SPs, EPs, and IPs subjectivating the protagonist and inviting her to reflect and self-observe. In terms of narrative richness, this excerpt offers greater variety and a more promising prospection.

\section{Main findings}

At a thematic level and in terms of structure, the narrative emerging from the initial therapeutic session focuses mainly on the relationship between the client and her daughter. There is relatively little self-referencing, which is expressed in terms of OEPs when it appears (i.e., as traits or states suggesting unmodifiable conditions). Subjectivation is scarce and negative; agency is confusing, as it is based on trying and having done something rather than on wanting to do it (therefore, although she suggests activity and accomplishments in the past, she expresses inhibition and frustration in the present); she does not seem to have a personal life plan. On the actantial plane, the protagonist appears as a compulsive giver who eventually "feels emptied." In terms of the plot, there is definitely a development based on the typical elements of a predominantly regressive narrative (which drifts along until it reaches the current drama). From that point onward, there is practically no prospection or possibility of evolution. Temporality is stagnant.

At the level of narrative functions, the client's narrative shows a predominance of PCCs and a poor use of PCMs at the beginning of the treatment; in addition, both PCCs and PCMs show qualitative characteristics leading to a closed concluding activity. There are RMKs, as well as mainly explanatory GCSs, which provide some complexity to the narrative and are used to account for the reason why things happened as they were. However, both have a linear structure, only serving to confirm the client's point of view. The protagonist might seem to be outlining a general panorama but without too much perspective (or under a single light) based on her official narrative.

In contrast, during the last session the client shows a richer and more complex narrative. At the level of structure and on the identity plane, greater self-referencing and a deeper self-characterization work can be observed. Both a new form of agency and a richer subjectivation seem to be outlined. On the actantial plane, the protagonist appears to review and question her role as a giver (in which she has sustained her positive sense of herself, albeit at a high personal cost). The result of all this is a more open change-enabling prospection.

At a functional level, the presence of PCCs and OEPs about "what the world is like" seems to decrease; when they are used, they are integrated into PCMs that relativize and put them into perspective. The number of rigid objectivating explanations appears to drop and new narratives emerge, with interpretations that make it possible to think about the experience in dynamic and multifaceted terms. Together with new and more complex PCMs, there are SPs, IPs, EPs, and EDPs referring to the protagonist's idiosyncratic motives and reasons, as well as those of the other characters. These types of predicates not only help to understand the protagonist's own actions and those of others, but they also provide them with nuances.

\section{Discussion}

\section{Current integration for the understanding of therapeutic change as a change in narratives}

The above suggests a significant change in the client's autobiographical narratives between one moment and another of her treatment. After the therapeutic process, the composition and coherence of the narrative analyzed seem to be modified. This can be observed in terms of i) selfreferencing: the different topics dealt with imply a greater existential involvement of the protagonist; ii) thematic multiplicity: new topics are incorporated according to the different moments and circumstances the protagonist is going through; iii) thematic relevance and cohesion: at the same time, a certain connection between the topics can be observed, which makes it possible to differentiate between peripheral and central topics; iv) a rich characterization of the characters: this includes the possibility not only of assigning the characters some stable characteristics (ontological traits, dispositions, etc.) - giving them certain referential identity - but also of including dynamic elements that make it possible to contemplate exceptions and particularities according to the circumstances; v) perspectivism: after the therapeutic process, the protagonist shows a greater disposition to review her official narrative and adopt other points of view; vi) recursion: the protagonist raises questions and reflections that make it possible to review and relativize any concluding or closed statements; vii) partial concluding activity: the protagonist makes some assumptions about herself, others, and the world, albeit not in an absolute or definite way; she is also able to relativize them, which allows her to adopt a novel position and a new prospection; viii) harmony and balance between the support functions: the new narrative offers a greater variety of support functions, as well as a certain harmony and equipresence in their distribution throughout the story.

A question emerging from our study is how to explain the differences shown by the analysis of both sessions. An obligatory question is whether those changes should be necessarily attributed to the therapeutic process. Something that needs to be taken into consideration is that clients' narratives may change over a period of several months as a result of external factors, most of which are 
unconnected with the treatment. Many things happen in people's daily lives that may lead them to reconstruct or reinterpret their stories. However, it is noticeable that the changes observed seem to express a fairly clear direction: the story in the last session shows many of the traits that Dimaggio and Semerari (2001) identify as typical of a coherent and effective narrative. This seems to coincide with several aspects mentioned by Mahoney (2005) in his clinical and theoretical considerations related to therapeutic change. He suggests that these aspects might be observed as changes in the characterization and complexity of the characters and the plot in clients' autobiographical narratives, as well as in their reinterpretations about the stories of their own lives.

Can such specific changes be explained only as something accidental caused by contingent aspects? Or is it credible to assign the therapeutic process a more or less significant role? The mere fact of telling one's own story systematically might help to resignify events in one's own biography. The possibility of having an agreeable place to do this exercise might constitute a (perhaps non-specific) factor contributing to therapeutic change. On the other hand, having an empathic trained expert who is able to listen, ask questions, and make appropriate remarks is likely to contribute an additional element to help in the process of reconstructing and rethinking about one's own autobiographical narratives. All of this might favor therapeutic change.

In relation to this, Stiles, Honos-Webb, and Lani (1999) understand the process of psychotherapeutic change in terms of schemata (Stiles et al., 1990). They consider that change reflects problematic experiences that are assimilated into the client's schemata. The successful therapeutic process may help the client to start building bridges of meaning between different voices and narratives. The consequent assimilation of experiences may result from linking and integrating, thanks to these bridges, memories that correspond to different coding levels in memory (implicit, semantic, procedural, and intentional memory). According to these authors, successful assimilation during therapy follows a predictable sequence describing different levels of assimilation of the problematic situation. The levels range from denial or being unaware of the problem, including a stage of clarification and acknowledgment of the problem, to considering alternatives or systematically selecting courses of action. The authors state that varying degrees of narrative integration may occur during each of these stages, which may translate into novel interpretation and action schemata. It is our belief that the results found coincide with an evolution throughout these different moments.

One of the assumptions of this paper is that autobiographical narratives might express aspects of one's own personal identity (Ricoeur, 1991, 2004). As autobiographical narratives change, clients' experiences with regard to themselves might also change. Something that should be investigated is the extent to which the changes expressed in the stories narrated by the client in this study are really associated with a change in her experience of personal identity and whether that is expressed independently of what narrative analysis allows us to capture. Certainly, it would involve carrying out another type of additional studies. To this end, it would be really important for us to be able to relate the results of narrative analyses with independent measures. In addition, it would be essential to evaluate the degree of stability expressed by the changes in narratives over time. These are all pending aspects in our study.

\section{Future research direction}

Following the previous line of thought and based on our findings and the literature review, we have asked the following question: What might be the main considerations that a therapist should take into account during a therapeutic process in order to help the client to restructure his or her biographical narrative in terms of theme, structure, and functions? Assuming a scale ranging from a lower level to one of greater narrative complexity, and considering the successive stages of the process, we may suppose that: i) in the face of a problematic event, a first step might be to narrate it, especially through CFPs describing the facts to be interpreted and signified later. This might allow the problematic material to emerge so that the client could symbolize it; ii) during the second step the client might struggle to conclude something out of the narrative above (fundamentally by appealing to OEPs, as well as EPs, in order to do so). During this stage, it would also be essential for the client to be able to recognize the subjective connotations emerging from the concluding activity (by using SPs, EPs, and IPs to this end). Based on the above, the client might begin to be able to reach an understanding of the problem that would enable him or her to reposition him or herself at the levels of both agency and actancy; iii) the third and last moment of the process might be oriented to reflection and perspectivation work, as well as to the most efficient integration of what has been previously concluded. This might enable the client to make informed decisions, attending not only to abstract aspects but also to deep feelings and motivations that would help him or her to resignify events. The use of PCMs formed on the basis of reflective SPs, EPs, and IPs would be key to this end. It goes without saying that this is just a proposal that will require new studies addressing, among other things, not only the type of pathology presented by the client who comes to consultation, but also the kind of problem for which he or she requests help. In addition, if the analysis procedure used here allowed us to observe substantive differences in relevant dimensions of the autobiographical narrative in two clearly distinct and opposite moments of the therapeutic process (beginning and end), it may be assumed that it might also permit us to identify intermediate stages throughout such 
transition. These variations of the autobiographical account might suggest the presence of key instances of the process of therapeutic change conceived as a reconstruction in the client's autobiographical narratives, which would deserve further research.

\section{Limitations of the study}

Among the limitations that we find in our study, it should be noted, on the one hand, that it is a first and only case that has been analyzed thoroughly and exhaustively. This conditions the possibility of generalizing any conclusions, although it provides us with some guidelines to think about the studied phenomenon. On the other hand, emphasis should be placed on the fact that the narrative belongs to a client diagnosed with depression; this might limit the scope of our results to this type of population exclusively. In addition, whether or not the results extend to psychotherapeutic procedures of different theoretical lines should be checked. Otherwise, the model is a relatively new procedure for the analysis of the psychotherapeutic process, since it was originally designed and applied - in its initial developments - to narratives from autobiographical interviews, and it is now in a study and adaptation phase to the context of psychotherapy. The model's dimensions and categories should be revised and corrected in order to provide greater validity to the analysis as a whole.

\section{Conclusions}

We consider that the model developed here provides elements for a dynamic and structural understanding of the process of construction and reconstruction of autobiographical narratives throughout different stages of the psychotherapeutic process. It is our belief that this analysis method might help to give us a better understanding of the mechanisms regulating continuity and therapeutic change (or, in contrast, the closure and obstruction of the therapeutic change) based on how our autobiographical narratives are structured. We believe that this method could also be used for future research into and design of novel therapeutic proposals. These could be based on the analysis and diagnosis of the client's narrative style and pay attention to the types of strategies determining the composition and narrative coherence of his or her autobiographical narrative. Once the predominant or typical strategies have been recognized, the therapist could intervene in order to favor a dialogue that helps the client to make them more flexible, and thus generate change-enabling narrative options.

\section{References}

Adler, J. M. (2012). Living into the story: agency and coherence in a longitudinal study of narrative identity development and mental health over the course of psychotherapy. Journal of Personality and Social Psychology, 102(2), 367-389.

Adler, J. M., Chin, E. D., Kolisetty, A. P., \& Oltmanns, T. F. (2012). The distinguishing characteristics of narrative identity in adults with features of borderline personality disorder: An empirical investigation. Journal of Personality Disorders, 26, 498-512.

Adler, J. M. \& McAdams, D. P. (2007). The narrative reconstruction of psychotherapy. Narrative Inquiry, 17, 179-202.

Adler, J. M., Wagner, J. W., \& McAdams, D. P. (2007). Personality and the coherence of psychotherapy narratives. Journal of Research in Personality, 41(6), 1179-1198.

Anderson, H. (1997). Conversation, language and possibilities: A postmodern approach to therapy. New York: Basic Books.

Anderson, H., \& Goolishian, H. (1992). The client is the expert: A not-knowing approach to therapy. In S. McNamee \& $\mathrm{K}$. J. Gergen (Eds.), Therapy as social construction. London: Sage.

Angus, L., \& Hardtke, K. (1994). Narrative process in psychotherapy. Canadian Psychology, 35, 190-203.

Angus, L., Levitt, H., \& Hardtke, K. (1999). The narrative processes coding system: Research applications and implications for psychotherapy practice. Journal of clinical psychology, 55(10), 1255-1270.

Avdi, E., \& Georgaca, E. (2007). Narrative research in psychotherapy: A critical review. Psychology and Psychotherapy: Theory, Research and Practice, 80(3), 407-419. doi: 10.1348/147608306X158092

Bamberg, M. (2012). Narrative Analysis. In H. Cooper, APA Handbook of research methods in psychology (3 volumes), Washington, DC: APA Press.

Baerger, D. R., \& McAdams, D. P. (1999). Life story coherence and its relation to psychological well-being. Narrative Inquiry, 9(1), 69-96.

Barthes, R. (1991). Introducción al análisis estructural del relato. En Eliseo Verón (Ed.). El análisis estructural. Buenos Aires: Centro de Editores de América Latina.

Bernasconi, O. (2011). Aproximación narrativa al estudio de fenómenos sociales: Principales líneas de desarrollo. Acta Sociológica, 56, 9-36.

Binswanger, L. (1956). Tres formas de la existencia frustrada. Amorrortu.

Binswanger, L. (1961). Artículos y conferencias escogidas. Madrid: Editorial Gredos, S.A.

Botella, L. (2008). Resultado y proceso en Psicoterapia Cognitivo-Construccionista Integradora. Apuntes de Psicología, 26(2), 229-241.

Botella, L., \& Cutura J. M. (2015). Narrative process in psychotherapy: Differences between good and poor outcomes clients. Acción Psicológica, 12(2), 123-142. doi: 10.5944/ap.12.2.15766

Botella, L., \& Gamiz, M. (2011). Narrative assessment in psychotherapy: A constructivist approach. Personal construct methodology, 245-267.

Brockmeier J. \& Harré, H. (1991). Narrative Problems and Promises of an Alternative Paradigm. In J. Brockmeier \& D. Carbaugh (Eds): Narrative Identity. Studies in Autobiography, Self And Culture. Amsterdam \& Philadephia: John Benjamins.

Bruner, J. (2003). La fábrica de historias. Derecho, literatura, vida. Buenos Aires: Fondo de cultura económica.

Bruner, J. (2004). Life as narrative. Social research: An international quarterly, 71(3), 691-710. 
Bruner, J. (2010). Realidad mental y mundos posibles: los actos de la imaginación que dan sentido a la experiencia. Barcelona: Gedisa.

Capella, C. (2013). Una propuesta para el estudio de la identidad con aportes del análisis narrativo. Psicoperspectivas, 12(2), 117-128.

Capella, C. (2017). Disequilibrium and Loss of Narrative Coherence in Identity Construction: A Piagetian Perspective on Trauma in Adolescent Victims of Sexual Abuse. Journal of Constructivist Psychology, 30(4), 323-338.

Carreras, X. \& Duero, D. G. (2012). Sentimiento de orientación vital y vivencia del cuerpo en personas impulsivas, con trastornos de la alimentación: un estudio fenomenológiconarrativo. Revista Argentina de Ciencias del Comportamiento, 4(3), 30-47.

Dimaggio, G., \& Semerari, A. (2001). Psychopathological narrative forms. Journal of Constructivist Psychology, 14(1), $1-23$.

Duero, D. G. (2006). Relato autobiográfico e interpretación: una concepción narrativa de la identidad personal. Atenea Digital, 9, 131-151.

Duero, D. G. (2010). Coherencia y composición en el relato autobiográfico: estrategias para su análisis e implicancias para la psicoterapia. Revista CES Psicología, 3(2), 18-47.

Duero, D. G., \& Córdoba, M. C. (2016). Análisis comparativo de los estilos narrativos de personas con síntomas depresivos y obsesivo-compulsivos. Revista Peruana de Psicología y Trabajo Social, 5(1), 27-51.

Duero, D. G., \& Córdoba M. (2017). Análisis fenomenológico narrativo de una persona con diagnóstico de trastorno obsesivo compulsivo, reconsideraciones sobre el cuadro clínico. Anuario de Investigaciones de la Facultad de Psicología, 3(1), 264-283.

Duero, D. G., \& Limón Arce, G. (2007). Relato autobiográfico e identidad personal: un modelo de análisis narrativo. AIBR. Revista de Antropología Iberoamericana, 2(2), 232-275.

Ellenberger, H.F. (1967). Introducción clínica a la fenomenología psiquiátrica y el análisis existencial. En Existencia. Rolo May, Ernes Angel y Henri Ellenberger (Eds.) Madrid.

Fernandes, E. M., \& Gonçalves, Ó. F. (1997). Exploração de construtos pessoais sobre o self em mudança em pacientes depressivos e agorafóbicos. Psicologia: teoria, investigaçao e prática, 2, 33-52.

Gergen, K. (1994). Realidades y relaciones. México: Editorial Paidos.

Gonçalves, O. F. (1995). Psicoterapia cognitivo-narrativa: La construcción hermenéutica de los significados de una nueva unidad observacional. Revista de psicoterapia, 6(22), 123-140.

Gonçalves, O. F. (2002). Psicoterapia cognitiva narrativa. Bilbao: Desclée de Brouwer.

Gonçalves, O. F., \& Machado, P. P. (1999). Cognitive Narrative Psychotherapy: Research Foundations. Journal of Clinical Psychology, 55(10), 1179-1191.

Gonçalves, O. F., Henriques, M., Alves, A., \& Rocha, C. (2001). Narrative process and complexity evaluation manual. Braga: Universidade do Minho.

Gonçalves O. F., Henriques M., Alves A., \& Soares L. (2002). Analyzing Structure, Process and Content in Narratives of Patients Diagnosed with Agoraphobia. International Journal of Clinical and Health Psychology, 2, 389-406.

Gonçalves, O. F., Henriques, M., \& Cardoso, G. (2001). Manual de avaliação da estrutura e coerência narrativa. Department of Psychology, University of Minho, Portugal.
Gonçalves, O. F., Henriques, M., Soares, L., \& Monteiro, A. (2001). Narrative content and multiplicity evaluation manual. Unpublished manuscript. University of Minho, Portugal.

Gonçalves, M. M., Matos, M., \& Santos, A. (2009). Narrative therapy and the nature of "innovative moments" in the construction of change. Journal of Constructivist Psychology, 22, 1-23. doi: 10.1080/10720530802500748

Gonçalves, M. M., Mendes, I., Ribeiro, A. P., Angus, L. E., \& Greenberg, L. S. (2010). Innovative moments and change in emotion-focused therapy: The case of Lisa. Journal of Constructivist Psychology, 23(4), 267-294.

Gonçalves, M. M., \& Ribeiro, A. P. (2012). Therapeutic change, innovative moments and the reconceptualization of the self: A dialogical account. International Journal of Dialogical Science, 6, 81-98.

Gonçalves, M. M., Ribeiro, A. P., Mendes, I., Matos, M., \& Santos, A. (2011). Tracking novelties in psychotherapy process research: The innovative moments coding system. Psychotherapy Research, 21, 497-509. doi: 10.1080/10503307. 2011.560207

Henriques, M. R., Machado, B. C., \& Gonçalves, Ó. F. (2002). Anorexia nervosa: A validação divergente de uma narrativa protótipo. International Journal of Clinical and Health Psychology, 2(1), 91-109.

Krause, M. (2005). Psicoterapia y cambio. Una mirada desde la subjetividad. Santiago: Ediciones Universidad Católica de Chile.

Lavov, W. \& Waletsky, J. (1967). Narrative analysis: oral version of personal experience. Journal of Narrative and Life History, 7(1-4), 3-38.

Lysaker, P. H. \& Lysaker, J. T. (2001). Psychosis and the disintegration of dialogical self-structure: Problems posed by schizophrenia for the maintenance of dialogue. British Journal of Medical Psychology, 74, 23-33.

Machado, B. C., Gonçalves, Ó. F., Machado, P. P., Henriques, M. R., Brandão, I., \& Torres, A. R. (2005). Anorexia nervosa e construção de significado: Validação divergente de uma narrativa protótipo. Comportamento alimentar. Revista de informação e divulgação científica do NDCA. Available from: https://www.researchgate.net/publication/242379771_Anorex ia_Nervosa_e_Construcao_de_Significado_Validacao_divergente_de_uma_narrativa_prototipo

Mahoney, M. (2005). Psicoterapia constructiva. Una guía práctica [Constructive Psychotherapy. A Practical Guide]. Barcelona: Ediciones Paidós Ibérica, S. A.

McLeod, J. (2011). Qualitative Research in Counselling and Psychotherapy. London: Sage.

Mergenthaler, E. \& Gril, S. (1996). Descripción de las reglas para la transcripción de sesiones de psicoterapia. Revista Argentina de Clinica Psicológica, 5(2), 163-176.

Moreira, P., Beutler, L., \& Gonçalves, O. (2008). Narrative change in psychotherapy: differences between good and bad outcome cases in cognitive, narrative, and prescriptive therapies. Journal of Clinical Psychology, 64(10), 1181-1194. doi: $10.1002 /$ jclp.20517

Neimeyer, R. A., \& Raskin, J. D. (2000). Constructions of disorder: Meaning-making frameworks for psychotherapy. Washington, DC: American Psychological Association.

Neimeyer, R. A., \& Stewart, A. (1996). Trauma, healing, and the narrative employment of loss. Families in Society: The Journal of Contemporary Social Services, 77(6), 360-375.

Orellana, G., Cantizano, L., \& Valdés, N. (2017) ¿Cómo hablan las pacientes introyectivas y anaclíticas? Microanálisis de las 
palabras utilizadas por pacientes depresivas durante el proceso psicoterapéutico. Revista Argentina de Clínica Psicológica, 23(3), 283-295. doi: 10.24205/03276716.2017.1028

Polkinghorne, D. (1988). Narrative knowing and the human science. In SUNY Seires in L. Langsdorf (Ed.) Philosophy of the Social Sciences. Albany: State University of New York Press.

Potter, J. (1996). Representing Reality: Discourse, Rhetoric, and Social Construction. London: Sage.

Propp, V. (1971). Morfología del cuento. Madrid: Editorial Fundamentos.

Ribeiro, A. P., Gonçalves, M. M., Silva, J. R., Brás, A., \& Sousa, I. (2016). Ambivalence in narrative therapy: A comparison between recovered and unchanged cases. Clinical Psychology \& Psychotherapy, 23(2), 166-175. doi: 10.1002/cpp.1945

Ribeiro, A. P., Mendes, I., Stiles, W. B., Angus, L., Sousa, I., \& Gonçalves, M. M. (2014). Ambivalence in emotion-focused therapy for depression: The maintenance of problematically dominant self-narratives. Psychotherapy Research, 24(6), 702-710. doi.org/10.1080/10503307.2013.879620

Ricoeur, P. (1978). Historia y Narratividad. Barcelona: Paidós, 1999.

Ricoeur, P. (1996). Sí mismo como otro. España: Siglo Veintiuno España S.A.

Ricoeur, P. (2004). Tiempo y narración I- II. Buenos Aires: Siglo XXI Editores.

Riessman, C. K. (2008). Narrative methods for the human sciences. California: Sage.

Salvatore, G., Conti, C., Fiore, D., Carcione, A., Dimaggio. G. \& Semerari, A. (2006). Disorganized narratives: problems in treatment and therapist intervention hierarchy. Journal of Constructivist Psychology, 19, 191-207.

Salvo, D., Cordes, K., \& Valdés, N. (2012). Observation Guideline for the Diagnosis of Depressive Symptoms. Santiago: Unpublished manuscript.

Soru, F., \& Duero, D. G. (2011). Experiencias corporales y sentimiento de orientación vital: una aproximación fenomenológica y narrativa. Revista de la Facultad de Psicología Universidad Cooperativa de Colombia, 7(13), 59-74.

Sousa, A. B. D., \& Cruz, J. P. (2008). Narrativa protótipo da depressão. Mudanças, 16(1), 71-80.

Spence, D. P. (1986). Narrative smoothing and clinical wisdom. In T. R. Sarbin (Ed.), Narrative psychology: The storied nature of human conduct. Westport, CT: Praeger.

Stiles, W. B., Elliott, R., Llewelyn, S. P., Firth-Cozens, J. A., Margison, F. R., Shapiro, D. A., \& Hardy, G. (1990). Assimilation of problematic experiences by clients in psychotherapy. Psychotherapy: Theory, Research, Practice, Training, 27(3), 411.

Stiles, W. B., Honos-Webb, L., \& Lani, J. A. (1999). Some functions of narrative in the assimilation of problematic experiences. Journal of Clinical Psychology, 55, 1213-1226.

Valdés, N., \& Krause, M. (2015). Verbal expressions used by anaclitic and introjective patients with depressive symptomatology: Analysis of change and stuck episodes within therapeutic sessions. Clínica y Salud, 26(2), 103-119.

Von Bergen, A., \& de la Parra, G. (2002). OQ-45.2, Outcome Questionnaire and Evolution of Psychotherapy: Adaptation, Validation and Guidelines for its Implementation and Interpretation. Terapia Psicológica, 20, 161-176. 